\title{
Bumba-meu-boi do Maranhão: uma releitura de seus primeiros registros sonoros
}

\section{Daniel Lemos Cerqueira}


O presente artigo tem como objetivo principal elaborar uma análise sonora das quatro gravações de bumba-meu-boi do Maranhão registradas em 1938 através da Missão de Pesquisas Folclóricas do Departamento de Cultura do município de São Paulo, coordenada por Mário de Andrade. Serão adotados como referência os padrões estéticos sonoros característicos da atual convenção de "sotaques", presente tanto em estudos acadêmicos quanto em documentos oficiais do governo do Maranhão, fazendo uso de referências da Etnomusicologia. De maneira a complementar a presente análise, serão discutidas questões acerca do método de documentação sonora e das políticas culturais voltadas à patrimonialização cultural, status em que se encontra atualmente a manifestação em pauta. Conclusões reforçam a imprescindibilidade de ampliar o conceito estabelecido de "cultura maranhense", historicamente sedimentado através das políticas culturais do governo estadual, e destacam a necessidade de haver mais estudos culturais sobre o Maranhão em uma perspectiva etnomusicológica.

Palavras-Chave: Bumba-meu-boi, Etnomusicologia, Políticas Públicas de Cultura

\section{INTRODUCÃO}

$\mathrm{H}$

á quase oitenta anos, sob a idealização e coordenação de Mário de Andrade (1893-1945) que na época dirigia o Departamento de Cultura do município de São Paulo, a Missão de Pesquisas Folclóricas percorreu o Norte e Nordeste do Brasil sob a finalidade de "realizar gravações de música popular tradicional nos seus locais originais" (SANDRONI, 2014, p. 56). Segundo o antropólogo Carlos Sandroni (2014, p. 56), após um primeiro estudo empreendido pela professora Oneyda Alvarenga nas décadas de 1940 e 1950, os fonogramas dessa missão permaneceram guardados em condições inadequadas por um bom tempo, sendo retomado o interesse no material somente na década de 1980. Recentemente, em 2006, o SESC/SP e a Prefeitura de São Paulo, em parceria, publicaram uma coleção de seis CDs com todos os registros sonoros. A íntegra do material se encontra disponível atualmente na internet para acesso livre em domínio mantido pelo SESC/SP (2016).

Em relação à passagem dessa missão no Maranhão, foram gerados vinte registros sonoros de manifestações locais selecionadas, sendo doze de tambor-de-mina, três de tambor-de-crioula, quatro de bumba-meu-boi e uma de carimbó (LACERDA, 2006) ${ }^{1}$. Segundo o Museu Afro Digital da

${ }^{1}$ O quantitativo de gravações de cada manifestação gera uma pergunta: seria o tambor-de-mina considerado mais representativo das tradições do Maranhão nessa época? É uma hipótese interessante para estudo. 
Universidade Federal do Maranhão (UFMA), os membros da missão também fotografaram alguns locais de São Luís, estando esses registros atualmente exibidos em uma página virtual (MUSEU AFRO DIGITAL, 2016).

Focando no bumba-meu-boi, manifestação intimamente representativa da identidade ${ }^{2}$ cultural do Maranhão na atualidade, suas quatro gravações foram realizadas no dia 19 de junho de 1938, tendo os seguintes "brincantes"': Manoel Secundino dos Santos, José Emetério, Raymundo Nonato, André Avelino da Anunciação, Gervásio Antonio dos Santos, Francisco Ribeiro, José Patrício, Maurício Antonio dos Santos, Pedro Costa, José Adelino dos Santos, Atílio Araújo dos Santos, José Alves de Souza, José Patrício Nascimento, Pedro Alves de Orlando, Leôncio Baptista de Jesus e Raymundo Diniz Ferreira (SESC/SP, 2016). O grupo em questão interpretou quatro "toadas" - termo em referência às canções compostas pelos grupos de bumba-meu-boi - intituladas "Oh Lua nova, Oh Lua cheia", "Estrela d’Alva alumiou!", "Meu boi urrou" e "Meu povo quando eu morrer!". Não foi feita menção ao "cantador" do grupo - figura de referência que inicia a interpretação da toada, cantando a cappella (solo), além de ser frequentemente o compositor do grupo.

Na perspectiva de promover uma análise sobre esses registros sonoros, o presente trabalho ${ }^{4}$ tem como objetivo realizar um estudo comparativo das toadas gravadas na Missão com as análises estético-musicais da atualidade sobre o bumba-meu-boi, procurando situá-las nas convenções definidas pelo "Complexo Cultural do Bumba-meu-boi do Maranhão: Dossiê de registro" (NUNES, 2011) e em pesquisas da Etnomusicologia, como as de Mukuna (2003), Santos Neto (2011) e Padilha (2014). Assim, pretende-se (re)contextualizar esses registros com base na prática contemporânea. Paralelamente, haverá uma breve discussão sobre os problemas do método de documentação sonora, amplamente difundido durante um momento da Etnomusicologia, e das políticas culturais estabelecidas pelo governo do Maranhão desde a década de 1960, voltadas à patrimonialização e à "cultura popular".

\footnotetext{
${ }^{2}$ Devido aos limites do trabalho, não haverá um aprofundamento sobre esse termo, problematizado tanto na Etnomusicologia quanto na Psicologia da Música. Aqui, indica-se o trabalho de Warden (2016), entre outros.

${ }^{3}$ Termo local referente a quem participa dos grupos de bumba-meu-boi - cujas apresentações também são chamadas de "brincadeiras". Na página do SESC/SP, os participantes são referenciados como "informantes".

${ }^{4}$ Artigo elaborado pelo Doutorado em Práticas Interpretativas do PPGM/UNIRIO, sob orientação do Prof. Dr. Marco Túlio de Paula Pinto e co-orientação do Prof. Dr. João Berchmans de Carvalho Sobrinho (UFPI), com financiamento do DEART/UFMA e da Fundação de Amparo à Pesquisa do Maranhão (FAPEMA)
} 


\section{Política Cultural e o BUMBA-MEU-BoI Do Maranhão}

$\mathrm{O}$ culto ao boi aparece em culturas de diferentes locais e épocas, como no Egito antigo, na região do Mediterrâneo, na Babilônia e na China, entre outros (VIANA, 2006, p. 30). No Brasil, o bumba-meu-boi é um dos diversos tipos de culto ao boi recorrentes em todo o território brasileiro, como o boi-bumbá do Amazonas e Pará, os bois de mamão e mourão de Santa Catarina e os bois-de-reis da região Norte Fluminense (NUNES, 2011, p. 18).

Sobre o surgimento do bumba-meu-boi no Brasil, o etnomusicólogo Kazadi wa Mukuna (2003, p. 12) afirma que ele provavelmente se deu junto ao ciclo do gado durante o Brasil Colonial, iniciando-se na Bahia para depois ir a Pernambuco e, posteriormente, para o Maranhão. A menção mais antiga ao bumba-meu-boi que se conhece hoje é uma notícia de jornal publicada no Recife em 1840 e intitulada "A estultice do bumba-meu-boi” (O CARAPUCEIRO, 1840). Trata-se de uma crítica feita pelo pe. Lopes Gama, avaliando a manifestação na perspectiva de uma ofensa à Igreja Católica. Os personagens descritos pelo padre são muito semelhantes aos presentes nos grupos maranhenses de hoje: havia o boi, a caipora (característica dos grupos da Ilha de São Luís), o sacerdote e o pajé. Já o pai é chamado de "Matheus" - no bumba-meu-boi do Maranhão, esse seria o pai Francisco. Essa é uma semelhança considerável, tendo em vista que o levantamento do IPHAN (NUNES, 2011, p. 20) menciona a existência de pelo menos uma centena de personagens distintos nos diversos folguedos do boi pelo Brasil. Diante desse fato, surge a seguinte dúvida: se essa manifestação existe em locais diversos e provavelmente não surgiu no Maranhão, por que o bumba-meu-boi se tornou o símbolo da identidade cultural justamente desse Estado?

Uma possível resposta provém das políticas culturais adotadas pelo governo do Maranhão desde a década de 1960. Segundo alguns estudiosos, entre eles Costa e Camelo (2011) e Padilha (2014), o bumba-meu-boi era proibido até o início do século XX no Estado assim como as demais manifestações afro-brasileiras, a exemplo do tambor de mina, tambor de crioula e do cacuriá. Segundo Costa e Camelo (2011, p. 1), no final do século XIX, as mesmas só poderiam acontecer no centro de São Luís mediante o patrocínio de pessoas influentes. A partir de então, tais manifestações foram progressivamente sendo permitidas, até que o Estado passou a reconhece-las 
oficialmente por meio de uma política cultural para valorizar os folguedos locais a partir de 1975, na gestão de Domingos Vieira Filho frente à Fundação Cultural do Maranhão (CERQUEIRA, 2016, p. 5-6). Um acontecimento simbólico de reconhecimento oficial pelo Estado, mencionado por Albernaz (2012, p. 8), foi a apresentação de um grupo de bumba-meu-boi do sotaque de Zabumba no Palácio dos Leões na década de 1960, a convite do então governador José Sarney ${ }^{5}$. Essa política, que permitiu inicialmente o "reconhecimento" do bumba-meu-boi, mantém-se até a atualidade, fazendo com que ele seja visto hoje como principal representante da "cultura maranhense" no Estado. Segundo o trompetista Antônio Francisco Padilha:

O processo de folclorização ofereceu ao bumba-meu-boi a oportunidade de apresentar o Maranhão ao mundo exterior. Neste sentido, ele tornou-se importante para os 'brincantes', que veem agora a oportunidade de a performance autorizada, e para os políticos que 'usam' o bumba-meu-boi como forma de promoção pessoal e coletiva. Esta política de consenso imaginado e, portanto, de interlocução, permitiu que o bumba-meu-boi fosse elevado a ícone emblemático do Maranhão. Podemos considerar que o uso do boi como argumento de identidade está configurado na sua utilização por parte da classe política, como objeto industrial e, em alguns casos, com interesse meramente eleitoral, alterando apenas a forma de dominação. (PADILHA, 2014, p. 15)

É interessante observar que o "objeto industrial" ao qual Padilha se refere trata da exploração de "folguedos" para fins de turismo, um mercado consolidado hoje no Maranhão através dessa política cultural. Como reflexo desse processo de apropriação da cultura pelo Estado, Cerqueira acrescenta:

Essa política de valorizar a 'identidade cultural' sempre privilegiava um mesmo grupo de artistas e companhias alinhados esteticamente ao que o Estado define como 'cultura maranhense', desencorajando a inovação artística e excluindo os demais profissionais da Cultura. (CERQUEIRA, 2016, p. 7)

\footnotetext{
${ }^{5}$ Segundo informação apresentada no minicurso de "História da Música no Maranhão", ministrado na Escola de Música do Estado do Maranhão (EMEM) em 23 e 24 de março de 2017 pelo autor do presente estudo, José Sarney "batizou” diversos grupos de bumba-meu-boi a partir do final da década de 196o. Tal fato revela um possível interesse eleitoral populista, concretizado com a colaboração de Domingos Vieira Filho - que, entre as décadas de 1950 e 196o, quando Sarney era presidente da Academia Maranhense de Letras, direcionou as políticas de cultura para a Literatura (CERQUEIRA, 2016, p. 3-4).
} 
O "ápice" dessa política ocorreu em 2011, com a "elevação" do bumba-meu-boi do Maranhão ao status de patrimônio cultural brasileiro (NUNES, 2011). A política de patrimonialização, cujo impacto mais forte provém do reconhecimento de determinadas manifestações pela UNESCO, gera o benefício de colocar em evidência práticas culturais que estariam sob "risco de desaparecimento". Por outro lado, as práticas transformadas em patrimônio tendem a se estagnar em termos estéticos, especialmente sob a ideia de uma "tradição" a ser mantida. Além disso, as mesmas são vistas como um recurso em potencial para exploração turística - que, naturalmente, possui aspectos positivos em termos de geração de renda. Entretanto, existe a tendência em beneficiar indivíduos em particular, pois ela se caracteriza por produzir um "recorte" local e temporal na prática cultural "contemplada". E no caso do Maranhão hoje, os maiores beneficiados pela patrimonialização do bumba-meu-boi acabam sendo os indivíduos em situações de poder na indústria do turismo e na política, e não os cantadores e brincantes - justamente aqueles que mais precisam de suporte.

Outro problema decorrente dessa política cultural é o foco na "cultura popular”'. Esse termo, problemático, é utilizado no Maranhão para denotar oposição à "cultura erudita". Essa diferenciação também é recorrentemente associada a classes sociais, a exemplo do posicionamento de Albernaz (2012, p. 5), onde a "cultura erudita" seria supostamente ligada a classes abastadas. Essa visão ultrapassada de erudito e popular não permite observar o que ocorre na atualidade: hoje, as elites estão muito mais próximas da "cultura popular", pois essa é capaz de gerar retorno financeiro e apelo social com muito mais evidência. Já a "cultura erudita" tem passado por grandes desafios para sua manutenção justamente por não ser mais o foco de interesse tanto das elites quanto da população em geral. O Maranhão é um dos exemplos mais ilustrativos desse fato: é um dos três Estados brasileiros que não possui uma orquestra profissional, mesmo possuindo um histórico relevante com essa formação musical especialmente durante a segunda metade do século XIX (CERQUEIRA, 2016, p. 2). Frente às políticas culturais que vem sendo adotadas, a tendência é que essa polarização continue marginalizando a "cultura erudita" - que também precisa ter o mesmo direito à manutenção da "cultura popular".

Segundo a historiadora Lia Calabre, o embrião da política de patrimonialização no Brasil remete à figura de Mário de Andrade, que colaborou no projeto de criação do Serviço de Patrimônio Artístico e Histórico Nacional (SPHAN). No momento, a ideia era de registrar como tombamento as

${ }^{6}$ Outro tema amplamente discutido na literatura. Nessa perspectiva, indica-se o trabalho de Neder (2011). 
manifestações e produções culturais e artísticas sem, no entanto, promover políticas de cultura (CALABRE, 2014). Trata-se, então, de uma ação museológica, fortemente ligada ao conceito de "tradição", e não concebe a cultura como um processo dinâmico e em constante intercâmbio, naturalmente sujeita a transformações ao longo do tempo. Nessa perspectiva, há uma concepção diferente na atualidade acerca do método de "documentação sonora". É nesse sentido que se pretende (re)contextualizar o trabalho empreendido na Missão de Pesquisas Folclóricas.

\section{Questões DA ETNOMUSiCOLOGia E A Missão de PESQUisas Folclóricas}

documentação na Etnomusicologia através de registros sonoros é
uma prática recorrente em seus métodos de investigação. Segundo
Sonoda (2010, p. 75), o método de registrar os sons de culturas em diversos lugares do mundo, a partir do final do século XIX, aproximou a Etnomusicologia - referenciada na época como "Musicologia comparativa" - da pesquisa de campo. Entretanto, o autor acrescenta que as abordagens comparativas adotadas nesse momento avaliavam a música "do outro" sob critérios supostamente "universais", baseados na cultura do pesquisador tratando-se, portanto, de uma concepção etnocêntrica.

A partir da década de 1950, há uma forte mudança nas concepções metodológicas da Etnomusicologia. Os registros sonoros e em audiovisual assumem a posição de uma ferramenta complementar à investigação, pois esses são incapazes de captar as manifestações culturais de maneira mais ampla, falhando na compreensão da música como um elemento intimamente relacionado a questões sociais, humanas e a outros tipos de expressões artísticas presentes no contexto em estudo. Sonoda acrescenta:

Seja porque o áudio isoladamente não fornece informações suficientes para se constatar algo sobre uma cultura, seja porque, geralmente, a música em contextos de transmissão oral apresentase como elemento indissociável de outros aspectos humanos e sociais [...] no final do século XX, os etnomusicólogos se voltam para a constituição de uma imagem tão completa quanto possível dos diversos fenômenos que constituem a música, indo em direção quase completamente oposta aos objetivos dos anos 1950 de investigação detalhada de uma única cultura musical (SONODA, 2010, p. 76) 
$\mathrm{Na}$ metodologia baseada em documentação por meio de registros sonoros apenas, é possível relacioná-la com o "colecionismo" na Arquivologia musical, uma referência à prática de coletar documentos musicais - partituras e gravações, por exemplo. Ao tratar sobre o método empregado pelo musicólogo Francisco Curt Lange em sua pesquisa sobre o repertório do Brasil Colonial, os musicólogos André Cotta e Pablo Sotuyo alertam:

\begin{abstract}
A prática de colecionar manuscritos musicais, à qual talvez a figura lendária do garimpeiro musical - como foi chamado Lange muitas vezes - tenha servido de estímulo, geralmente implica na seleção de certos documentos sob um determinado critério científico ou artístico, desprezando os documentos restantes, quebrando laços orgânicos e contribuindo para a sua destruição. Temos chamado essa prática de colecionismo e acreditamos que ela deve ser vivamente repudiada, na medida em que implica na fragmentação dos arquivos, contribui para a sua destruição e traz prejuízos em termos de informação. (COTTA; BLANCO, 2004, p. 25)
\end{abstract}

Assim, ao trabalhar no material da Missão de Pesquisas Folclóricas, o pesquisador deve estar atento a esse debate. Logicamente, não se questiona a validade desse importante trabalho empreendido sob a liderança de Mário de Andrade, cujo método foi desenvolvido à luz das práticas de seu tempo. Entretanto, é interessante (re)contextualizar esses documentos sonoros com base nas práticas musicais da atualidade quando possível, fazendo com que eles se relacionem com o presente e possam ser entendidos para além da perspectiva do registro de um momento histórico pontual.

\title{
ESTUDO COMPARATIVO SOBRE A SONORIDADE DO BUMBA-MEU-BOI DO MARANHÃO
}

primeira questão evidenciada no registro sonoro do bumba-meu-
-boi realizado em 1938 diz respeito ao fato de que os mesmos intér-
pretes - "brincantes" - tomaram parte nas quatro gravações. Conforme a prática vigente na atualidade, é provável que se trate então de um mesmo grupo e, portanto, de um mesmo "sotaque". Conforme uma convenção proposta inclusive no documento do IPHAN (NUNES, 2011, p. 100) e respeitando individualidades inerentes a cada grupo, um sotaque é definido por um conjunto de características estéticas semelhantes (para "nós" musi- 
cais, indumentárias, cênicas e de organização espacial da dança) e territoriais (localidade de origem do grupo), formando um "estilo" próprio. Em diálogo com a Musicologia, Jan LaRue, ao tratar sobre o conceito de estilo na música de concerto, propõe uma definição que pode ser relacionada ao contexto das toadas de bumba-meu-boi, caso se entenda "peça" como "toada", "compositor" como "grupo" e "escola" como "sotaque":

[...] podemos perceber um estilo distinto em um grupo de peças a partir do uso recorrente de decisões similares; e o estilo característico de um compositor pode ser descrito em termos de consistência e preferências mutáveis em seu uso de elementos musicais e procedimentos. De forma mais abrangente, características em comum podem individualizar uma escola inteira ou um período cronológico. À medida que essas decisões compartilhadas se tornam mais gerais, sua aplicação por um compositor em particular diminui. (LARUE, 1992, p. ix)

Atualmente, há cinco sotaques convencionados nos grupos de bumba-meu-boi, tomando como referência o documento do IPHAN e a classificação feita pelo governo do Estado na organização dos festejos juninos - evento anual onde os grupos de bumba-meu-boi se apresentam sob patrocínio do governo. Adiante, serão abordadas somente as características das manifestações sonoras - o objeto de estudo aqui pretendido - de cada sotaque, levando em consideração as interpretações de Mukuna (2003), Padilha (2014) e do musicólogo Joaquim Antônio dos Santos Neto (2011), que elaborou uma análise motívica e adaptações em notação tradicional de toadas selecionadas que ilustram grupos ligados a cada um dos cinco sotaques do bumba-meu-boi. Junto às considerações, serão indicados os gestos musicais que mais claramente expressam a identidade musical de cada sotaque independentemente do instrumento, compreendidos como "embriões" de referência para as variações naturalmente elaboradas pelos grupos:

1 Sotaque de Zabumba ou de Guimarães: considerado o estilo mais antigo de bumba-meu-boi do Maranhão, tem como características musicais o uso de zabumbas, tambor-onça - instrumento semelhante à cuíca, mas que produz sons mais graves ${ }^{8}$ - tamborinho - também chamado de pandeirito - tambores de fogo - que lembram os instrumentos utilizados no tambor-de-crioula, fortemente relacionados aos tambores n'goma (CARVALHO, 2006, p. 265-266)

\footnotetext{
${ }^{7}$ A melhor analogia com o termo "compositor" seria "cantador": todo grupo possui um cantor que é intérprete das toadas e que também compõe a maior parte delas. Porém, como o grupo e o cantador são figuras que possuem ligação íntima no bumbameu-boi do Maranhão, faz mais sentido aqui propor uma analogia entre "compositor" e "grupo".

${ }^{8}$ Mukuna (2003, p. 84) propõe haver uma relação metafórica entre o som do tambor-onça e o mugido do boi.
} 
- e maracás de metal, entre outros instrumentos. Apesar de Santos Neto (2011, p. 54-68) e Padilha (2014, p. 51-52) utilizarem a métrica binária simples para representar o gesto musical desse sotaque, acredita-se que a métrica quaternária seja mais apropriada. Assim, segue adiante um gesto musical que pode ser associado à identidade sonora do sotaque em questão (Exemplo Musical 1):

Exemplo Musical 1. Gesto musical PRoveniente do sotaque de zabumba.

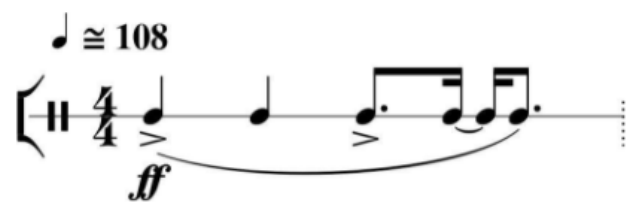

2 Sotaque de Matraca ${ }^{9}$ ou da Ilha: ligado à região da Ilha de São Luís, tem como instrumentos mais frequentes matracas de vários tamanhos - e que, portanto, produzem sons de alturas variadas - pandeirões - possuidores de membranas com grande superfície, sem platinelas - e maracás. Há, ainda, um grande maracá metálico que é utilizado pelo "cantador" ou "amo", o intérprete das toadas, e que produz um som de grande intensidade. $\mathrm{O}$ uso de uma potência sonora forte, inclusive, é uma característica do sotaque da Ilha. Outro instrumento presente é o apito, utilizado no início e no fim das toadas como uma espécie de "chamada" (convocação) para o grupo - também presente no tambor-de-crioula. Outra particularidade do sotaque da Ilha é a sobreposição de estruturas rítmicas conceito similar à polirritmia e que, nesse caso específico, é bem representado pelas proporções de duração da notação tradicional (Exemplo Musical 2):

Exemplo Musical 2. Gesto musical proveniente do sotaque da Ilha.

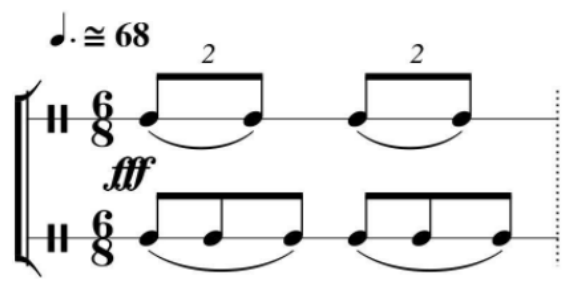

\footnotetext{
${ }_{9}^{9}$ Rogério Leitão, professor de percussão da EMEM, não concorda com o termo “Matraca” nessa definição, pois este não é o único "sotaque" que faz uso desse instrumento.
} 
3 Sotaque de Pindaré ou da Baixada: típico da planície chamada de "baixada maranhense", esse sotaque se constitui frequentemente de matracas, pandeirões e tambores-onça. A forma de identificação sonora desse estilo em relação aos demais se dá mais pelas células rítmicas do que pelos instrumentos utilizados, além de não seguir uma proporção temporal matemática conforme subentendida na notação musical tradicional. Segue adiante uma proposta de gesto musical para o mesmo, onde o posicionamento da cabeça das notas indica tipos de ataque diferentes em um instrumento de percussão capaz de gerar alturas distintas - sendo o som mais grave representado pela cabeça posicionada na linha e o mais agudo pela cabeça no espaço imediatamente superior à linha (Exemplo Musical 3):

Exemplo Musical 3. Gesto musical proveniente do sotaque da Baixada.

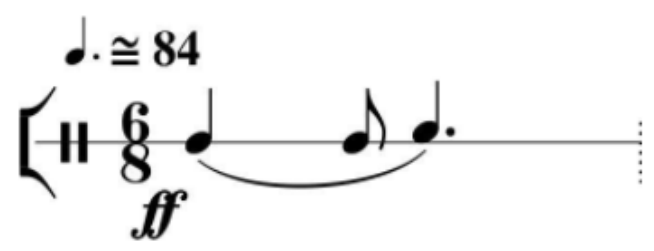

4 Sotaque de Costa-de-mão ou de $\operatorname{Cururupu}^{10}$ : seu surgimento é relacionado ao município de Cururupu, e tem essa denominação devido ao ataque feito com o dorso da mão em seus pandeiros característicos. Faz uso recorrente de maracás, tambores-onça e "pandeiros" - tratam-se de pandeirões com tamanho menor, e não de pandeiros com platinelas - além de caixas-de-guerra (taróis). A seguir, apresenta-se uma representação para o gesto musical identitário desse sotaque (Exemplo Musical 4):

Exemplo Musical 4. Gesto musical proveniente do sotaque de Cururupu.

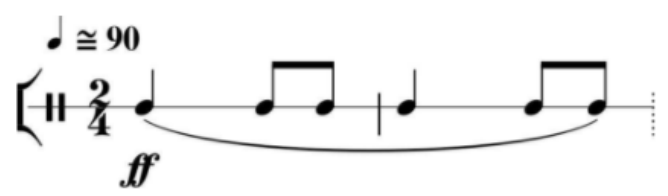

\footnotetext{
${ }^{10}$ Em São Luís, há uma informação recorrente sobre o possível "desaparecimento" desse sotaque devido aos poucos grupos que se apresentam nos festejos juninos. Segundo informação colhida no mencionado minicurso de "História da Música do Maranhão", a maioria dos grupos do sotaque de costa-de-mão não tem interesse em se apresentar na capital. Trata-se, portanto, de um equívoco gerado pela tendência centralizadora da política cultural de festejos: não há valorização ou mesmo conhecimento das ações culturais existentes no interior do Estado.
} 
5 Sotaque de Orquestra: sua natureza é atribuída à região do rio Munim, por volta da década de 1940 (PADILHA, 2014, p. 85). Originou-se mediante o intercâmbio entre grupos de bumba-meu-boi e bandas de fanfarra, formação presente em todo o Maranhão desde o final do período colonial e de fundamental importância para a manutenção das práticas musicais (CERQUEIRA, 2017, p. 6-7). Além de utilizar instrumentos artesanais de percussão típicos dos outros quatro sotaques, os grupos de Orquestra fazem uso de instrumentos dos naipes de metais e, em menor recorrência, madeiras. No caso desse sotaque, não é possível atribuir um gesto musical gerador para a manifestação sonora, pois ele utiliza elementos musicais estruturantes dos demais sotaques. Atualmente, muitos grupos associados ao sotaque de Orquestra são definidos nas políticas culturais do Estado como "alternativos" ou "parafolclóricos". Segundo o documento do IPHAN:

Atualmente identifica-se o surgimento de grupos com propostas artísticas com o objetivo de apresentar resumos e releituras de manifestações culturais populares. São os denominados grupos alternativos, uma terminologia forjada pelo poder público para classificar grupos que não se enquadram nos padrões já definidos dos grupos considerados tradicionais. Assim 'alternativo' tornouse uma categoria que se contrapõe ao que é considerado mais convencional na cultura popular maranhense. (NUNES, 2011, p. 195)

Portanto, mesmo possuindo ampla projeção na sociedade, o sotaque de orquestra não é visto com a mesma "legitimidade" dos demais sotaques em termos de "tradição" - ficando em posição inferior no sentido de valorização como "cultura maranhense".

\section{As gravaÇões da Missão de Pesquisas Folclóricas}

"Oh Lua nova, Oh Lua cheia" segue a forma mais frequente das toadas de bumba-meu-boi: há uma exposição inicial da "melodia” principal a cappella pelo cantador, com os versos principais da toada. Posteriormente, os demais brincantes cantam essa melodia em coro, juntamente com a entrada dos instrumentos musicais. A toada é encerrada com um apito - a "chamada" do grupo, conforme fora mencionado. A instrumentação utilizada possui matracas e um tambor grave, semelhante ao timbre de um tambor de fogo, que faz dois tipos de ataque distintos - um mais grave com a membrana livre e outro mais agudo apoiando a membrana para inibir sua vibração, semelhante aos toques da zabumba no sotaque da Baixada. Já as matracas apresen- 
tam uma regularidade rítmica compatível com a sua representação proposta na notação tradicional.

As melodias entoadas pelos cantadores sugerem uma forte influência das escalas modais típicas da música do Nordeste brasileiro, mas cuja representação na notação musical tradicional consistiria apenas em uma "aproximação" com o temperamento igual. Apesar disso, é possível perceber nesse caso o uso de um modo semelhante ao eólio.

De acordo com a instrumentação, essa toada estaria mais alinhada às convenções atuais do sotaque da Ilha, porém, a sobreposição rítmica apresentada anteriormente (ver o Exemplo Musical 2), característica desse sotaque na atualidade, não ocorre o tempo todo - e quando ocorre, aparece de maneira deslocada. Além disso, o andamento é mais lento do que o observado no sotaque da Ilha atual, e seu caráter cadenciado remete mais ao sotaque da Baixada. Foram identificados dois possíveis gestos musicais geradores das estruturas rítmicas da toada analisada (Exemplo Musical 5):

Exemplo Musical 5. Dois possíveis gestos musicais geradores na toada “Oh Lua nova, Oh Lua cheia”

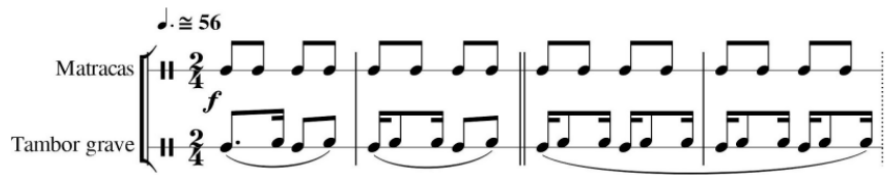

$\mathrm{Na}$ audição da toada seguinte, "Estrela d'Alva alumiou!", a forma musical segue o padrão adotado na toada anterior. No entanto, o coro é acompanhado inicialmente pelas matracas, com o tambor grave entrando mais adiante. Aqui, foi possível estabelecer outra interpretação para o gesto musical gerador do acompanhamento percussivo (Exemplo Musical 6), cujas notas em cor cinza representam aproximações da divisão temporal:

Exemplo Musical 6. Um possível gesto musical gerador na toada “Estrela d’Alva alumiou!".

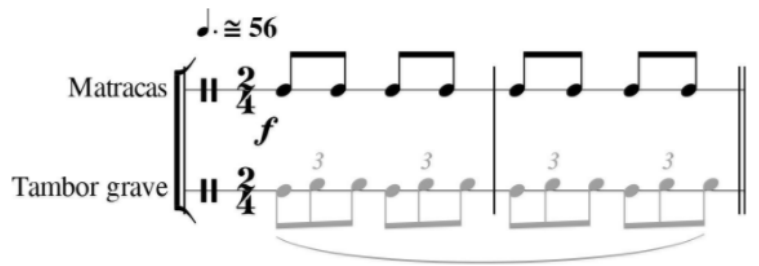


Conforme destacado através da notação em cor cinza, a representação rítmica nesse caso não deve ser interpretada segundo as proporções matemáticas de divisão das durações. Logo, é mais coerente pensar em sobreposições rítmicas não medidas de maneira matemática, mas que ainda possuem uma clara regularidade nas repetições. Essa é, inclusive, uma característica mantida no sotaque da Baixada atual. Já as matracas em "Estrela d’Alva alumiou!" são atacadas sob uma métrica regular, sendo a notação tradicional suficiente para representa-las nesse caso específico.

O registro sonoro seguinte, de "Meu boi urrou", se inicia já com o coro e os instrumentos, não havendo o recitativo inicial. O contorno melódico é bem característico da música do Nordeste brasileiro, com uso frequente de elementos análogos a arpejos ascendentes e descendentes de tétrades. As matracas apresentam o mesmo ritmo regular das toadas anteriores, mas dessa vez, algumas delas dobram a estrutura rítmica feita pelo tambor grave, gerando uma sonoridade mais semelhante ao sotaque da Ilha conforme a convenção da atualidade.

A última gravação, "Meu povo quando eu morrer!", se inicia com o recitativo, a exemplo das duas toadas iniciais. A melodia é bem mais longa que as apresentadas nas três toadas anteriores, fato que certamente se relaciona ao fato de possuir um desenvolvimento de duração também maior. Assim, uma diversidade maior de variações rítmicas foi apresentada, remetendo às possibilidades de variação feitas pelo pandeirão no sotaque da Baixada atual. Segue adiante um exemplo do gesto musical gerador observado nessa gravação (Exemplo Musical 7):

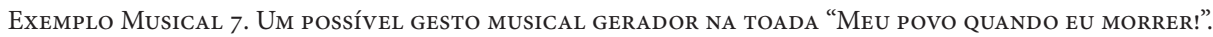

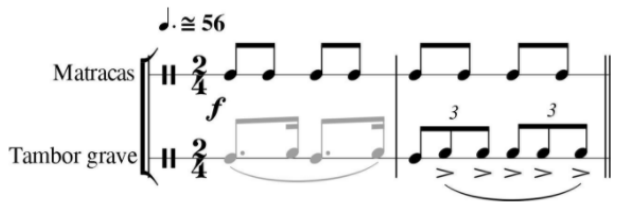

Com relação à letra das toadas - que, a exemplo do trabalho de Santos (2011), costumam ser equivocadamente analisadas como se fossem as toadas por completo e ignoram o fato de que canções são um híbrido entre Música e Literatura $^{11}$ - não é possível perceber uma linearidade no discurso

\footnotetext{
${ }^{11} \mathrm{O}$ etnomusicólogo Tiago de Oliveira Pinto chama a atenção para esse tipo de falha metodológica: "Um mal-entendido comum entre pesquisadores não familiarizados com a documentação musical é que pensam estar analisando e falando de música, quando na verdade discorrem sobre a letra" (OLIVEIRA PINTO, 2001, p. 222). Seria interessante tornar mais claro os aspectos em foco no estudo: como exemplo, a proposta realizada aqui é analisar a expressão sonora do discurso musical, e não a expressão literária, mas sem deixar de reconhecer que essa última é parte constituinte da manifestação - assim como a dança e as indumentárias, entre outros.
} 
literário ao longo das peças registradas. Ressalta-se que a ordenação das toadas ao longo de uma apresentação é feita com base em uma lógica linear, contando uma história - no caso, o drama folclórico do boi, desde a amputação de sua língua, os dilemas do pai Francisco, a perseguição e a ressurreição do boi pelo pajé. As quatro gravações geradas pela Missão consistem no recorte de algumas toadas provavelmente escolhidas pelo grupo como as mais representativas. Sendo assim, não há como verificar a ordem do repertório com base no enredo - ou mesmo saber se havia uma preocupação com essa ordenação na época.

Por fim, esses registros sonoros representam um recorte temporal do processo de mudanças estéticas do bumba-meu-boi ao longo do tempo, tanto que não é possível afirmar em qual sotaque essas quatro toadas se "enquadrariam". Esse processo "culminaria" cerca de meio século depois no estabelecimento da divisão convencionada de sotaques, sugerindo que, anteriormente, as características dos grupos eram mais "híbridas" e não comportavam essa classificação - ou "rotulação". Ainda, as gravações ilustram um repertório de toadas que circulava na época cuja grande maioria provavelmente se perdeu devido a uma interrupção na oralidade, pois as toadas são substituídas quando outro cantador entra no grupo. Há também casos onde os grupos são extintos, ocasionando o esquecimento completo de suas toadas. $\mathrm{Na}$ atualidade, é motivo de preocupação a política cultural que, ao estabelecer oficialmente uma classificação de sotaques, leva muito mais à padronização estética dos grupos - até por uma questão de "sobrevivência", pois os mesmos precisam se adequar às políticas para obter recursos - do que suscitar o intercâmbio, a diversidade e a criação nos mesmos. Isso sem contar a tendência de marginalizar todas as outras manifestações artísticas e culturais do Maranhão que não são reconhecidas como "cultura maranhense" nos termos estabelecidos pelo governo do Estado. Além disso, essa política cultural voltada somente à apresentação em festejos juninos não gera um desenvolvimento sustentável para os próprios grupos de bumba-meu-boi, pois não se estabelece uma agenda anual regular de apresentações, uma formação de centros culturais para cada grupo nem possibilita a documentação da história e memória dos mesmos. 


\section{ConsideraÇões Finais}

\pera-se que o presente trabalho possa contribuir para a discussão sobre algumas questões relativas ao bumba-meu-boi, especialmente sobre políticas culturais e a forma como o governo do Estado tem se apropriado de manifestações semelhantes visando à manutenção de uma concepção manipulada de "cultura maranhense". Ainda, acrescenta-se a problemática da política de patrimonialização, que tende a polarizar e discriminar manifestações específicas em relação a outras em uma mesma localidade ou região, gerando desigualdades políticas, sociais e culturais. Com relação aos trabalhos existentes sobre o bumba-meu-boi, é importante destacar que abordagens etnomusicológicas acerca do mesmo ainda são escassas, vindo o presente trabalho se somar, dentro de seus limites, às contribuições de Mukuna (2003), Santos Neto (2011) e Padilha (2014). Por fim, espera-se que a presente análise possa oferecer ideias sobre como reinterpretar o material produzido pela Missão de Pesquisas Folclóricas, gerando novos significados para o mesmo a partir de releituras e evitando deixa-lo relegado somente ao registro documental per se. 


\section{REFERÊNCIAS}

ALBERNAZ, L. S. F. Dinâmicas do bumba-meu-boi maranhense: classificação em 'sotaques’ e participação do público. Olhares Sociais, v. 2, n. 2, p. 3-24, 2012.

CALABRE, L. Práticas culturais e processos de patrimonialização: a ação das políticas culturais e o jongo do Sudeste como um possível estudo de caso. Estudos de Sociologia on-line, v. 1, n. 20, 2014.

CARVALHO. J. J. A Tradição Musical Iorubá no Brasil: um cristal que se oculta e se revela. In: QUEIROZ, R. C.; TUGNY, R. P. (Org.). Músicas africanas e indígenas no Brasil. Belo Horizonte: EDUFMG, 2006, p. 265-296.

CERQUEIRA, D. L. Políticas culturais para a Música no Maranhão: um breve estudo. Encontro Brasileiro de Pesquisa em Cultura, 4, Manaus, AM. Anais... UFAM, Manaus, AM, Novembro 09 a 11, 2016, p. 1-12.

Políticas Públicas de Cultura para a Música em Estados brasileiros: um estudo comparativo. Seminário Internacional de Políticas Culturais, 8, Rio de Janeiro, RJ. Anais... Fundação Casa de Rui Barbosa, Rio de Janeiro, RJ, Maio 23 a 26, 2017, p. 1-11.

COSTA, A. S.; CAMÊLO, J. P. C. A discriminação do bumba-meu-boi nos discursos dos diários do século XIX. Simpósio de História do Maranhão Oitocentista, 2, São Luís, MA. Anais... Uema, São Luís, MA, Junho 07 a 10, 2011, p. 1-9.

COTTA, A. G.; BLANCO, P. S. Arquivologia e Patrimônio Musical. Salvador: UFBA, 2004.

LACERDA, M. B. (org.). CD 5: Paraíba e Maranhão. 1 CD (69 min). In: LACERDA, M. B. Mário de Andrade: Missão de Pesquisas Folclóricas. São Paulo: SMC/ SESC-SP, 2006. 6 CDs.

LARUE, J. Guidelines for Style Analysis. Warren: Harmonie Park Press, 1992. 286p. $2^{\mathrm{a}} \mathrm{ed}$

MUKUNA, K. An Interdisciplinary study of The Ox and the Slave (Bumba-meu-boi): a satirical music drama in Brazil. Lewiston: Edwin Mellen Press, 2003.

MUSEU AFRO DIGITAL. Missão de pesquisas folclóricas de Mário de Andrade 1938. São Luís: UFMA, 2016. Disponível em <http://www.museuafro.ufma.br/site/ index.php/missao-de-pesquisas-folcloricas-de-mario-de-andrade-1938>. Acesso em 07/12/2016. 
NEDER, A. O estudo cultural da música popular brasileira: dois problemas e uma contribuição. Per Musi, n. 22, p. 181-195, 2010.

NUNES, I. M. A. (org.). Complexo Cultural do Bumba-meu-boi do Maranhão: Dossiê de registro. São Luís: IPHAN/MA, 2011.

O CARAPUCEIRO, Recife, p. 1-4, 11 jan. 1840.

OLIVEIRA PINTO, T. Som e Música. Questões de uma Antropologia Sonora. Revista de Antropologia, v. 44, n. 1, p. 221-286, 2001.

PADILHA, A. F. S. A construção ilusória da realidade, ressignificação e recontextualização do Bumba meu Boi do Maranhão a partir da Música. Tese de Doutorado em Música. 231f. Aveiro: Programa Doutoral do DECA/UA, 2014.

SANDRONI, C. O acervo da Missão de Pesquisas Folclóricas, 1938-2012. Debates, n. 12, p. 55-62, jun-2014.

SANTOS, J. M. S. As toadas do bumba-meu-boi: sobre enunciados de um gênero discursivo. Tese de Doutorado em Linguística e Língua Portuguesa. 268f. Araraquara: PPGLLP/UNESP, 2011.

SANTOS NETO, J. A. A Música no Bumba-meu-Boi do Maranhão. In: NUNES, I. M. A. (org). Bumba-meu-Boi: som e movimento. São Paulo: IPHAN, 2011, p. 15-99.

SESC/SP. Missão de Pesquisas Folclóricas. São Paulo: SESC/SP, 2016. Disponível em <http://ww2.sescsp.org.br/sesc/hotsites/missao >. Acesso em 07/12/2016.

SONODA, A. V. Tecnologia de áudio na Etnomusicologia. Per Musi, n. 21, p. 74-79, 2010.

VIANA, R. N. A. O bumba-meu-boi como fenômeno estético. Tese de Doutorado em Educação. 181f. Natal: PPGE/UFRN, 2006.

WARDEN, N. Ethnomusicology's 'Identity' Problem: The History and Definition of a Troubled Term in Music Research. El Oído Pensante, v. 4, n. 2, p. 1-21, 2016. 